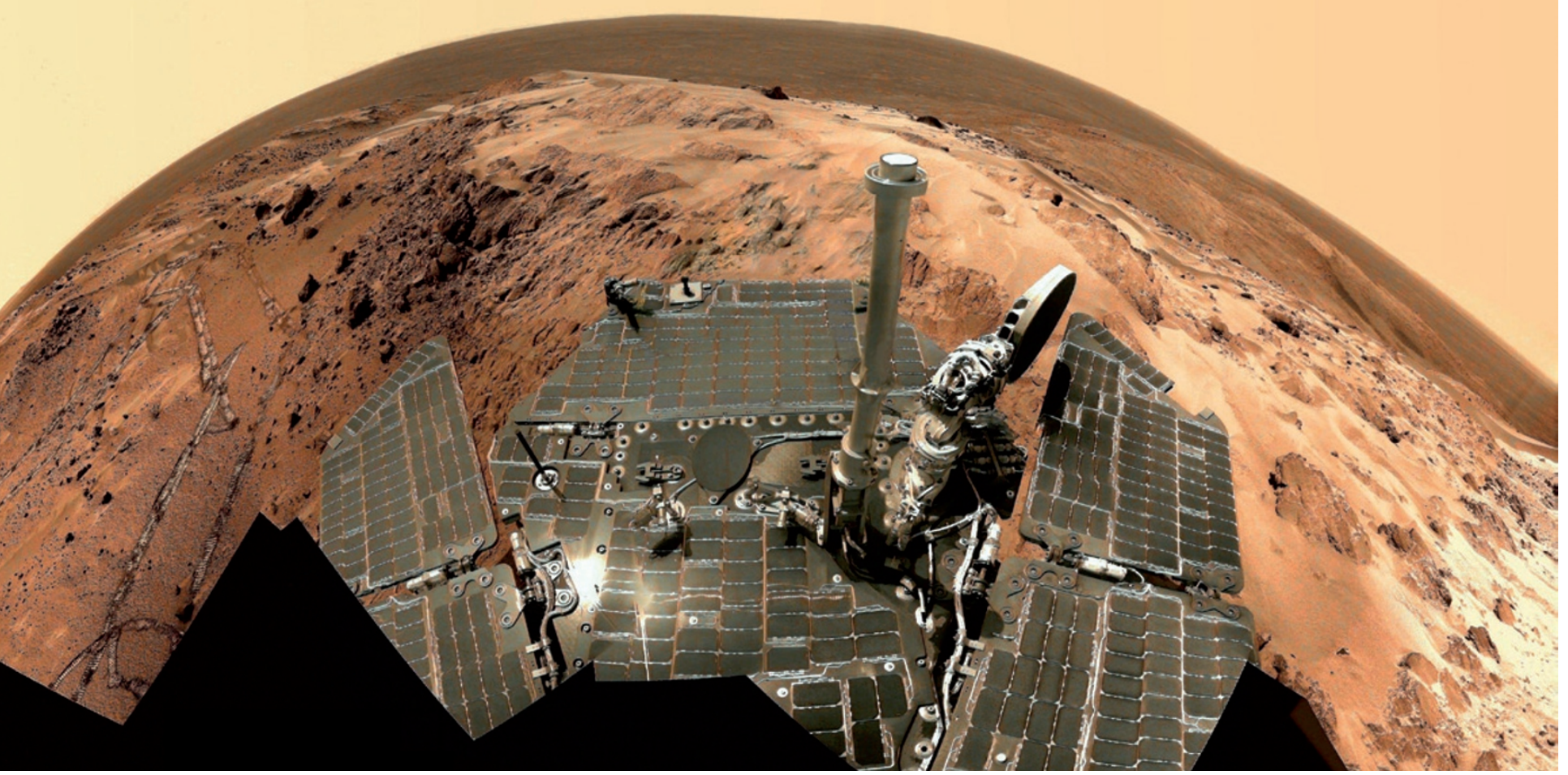

NASA's Spirit rover landed in the Gusev Crater on Mars in January 2004.

MARS EXPLORATION

\section{Roving the red planet}

\section{It is people who drive Curiosity and other robot missions on Mars, reminds Jim Bell.}

$\mathrm{T}$ here are Martians among us. Hundreds of them, living on Earth but working 'on' Mars, telecommuting to and fro as part of the interplanetary science and exploration programme conducted by NASA and other space agencies. These Martians are the men and women who help to control robots such as the Mars rovers on the red planet's surface, or any of the three satellites orbiting Mars and acquiring remotesensing data. But both the media and the public tend to anthropomorphize the rovers as the explorers in this frontier world.

Cognitive scientist William Clancey, based at NASA's Ames Research Center in Moffett Field, California, works on how humans and societies adapt their lives and work to computers. During the early years of the Spirit and Opportunity missions, Clancey embedded himself in the Mars Exploration Rover (MER) science and engineering team at NASA's Jet Propulsion Laboratory in Pasadena, California. His Working on Mars documents firsthand many of the highs and lows of the people trying to carry out remotely controlled field science over a vast distance using mobile, programmable laboratories.

By observing these Martian "natives" and interviewing a subset of the science and engineering teams, Clancey captures some of the complex inner workings of a modern scientific expedition that just happens to be on another planet. And he draws analogies to eighteenth- and nineteenth-century expeditions such as those of James Cook and Alexander von Humboldt.

The rovers' missions have become major media and sociological phenomena. The starry roster now includes the 1997 Mars Pathfinder Sojourner rover, the MER Spirit and Opportunity, which landed in 2004 (Opportunity is still active), and NASA's newest interplanetary vehicle, the car-sized

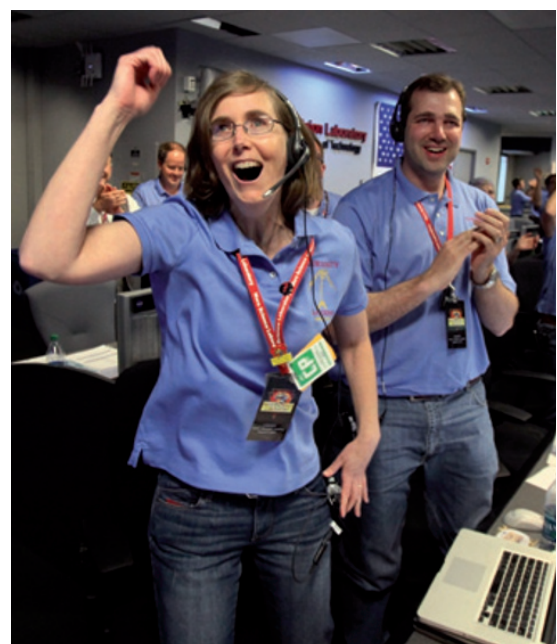

The team in charge of Curiosity celebrates the first pictures sent back from the red planet.
Curiosity rover that landed in early August. Millions of people worldwide, including educators and their students, have followed the missions online - an opportunity itself made possible mostly through the commitment of the rover science teams and NASA to share the adventures as widely as possible.

So the anthropomorphizing - which happens even among scientists working with the rovers - is perhaps not surprising. The robots are seen as having human-like senses: vision (cameras), touch (arms and drills) and taste (chemical analysis), as well as mobility (wheels). They are viewed as "plucky" or "intrepid", and during their missions "struggle" and "make discoveries". Among my colleagues on the rover science teams, it is common to refer to them as "robot geologists" or, in the case of Curiosity, a "robotic astrobiologist". Ultimately, even Clancey has to admit that casting the robots as valiant explorers in a dangerous land has heightened public interest in them - and perhaps even boosted public and Congressional support for NASA and its planetary-science missions.

Clancey underlines the importance of the unique and unprecedented sociotechnological fusion of remote sensors and the organizational structure, tactical-operations processes and strategic-planning tools pioneered by the MER team (many by trial and error and learning on the fly). Together, these promote the agency of the scientists and engineers and boost their capacity to actively and efficiently engage in scientific fieldwork in remote environments and situations.

One prime example is the way in which the MER planning software for rover driving and instrument deployment integrates the actual geology and

DNATURE.COM

For more on the Curiosity rover: nature.com/curiosity 


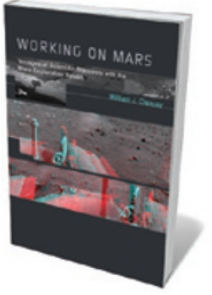

Working on

Mars: Voyages

of Scientific

Discovery with the

Mars Exploration

Rovers

WILLIAM J. CLANCEY

MIT Press: 2012

328 pp. $\$ 29.95$,

$£ 20.95$

topography of the rover's environment. Using previous days' imaging, it produces a fully functional computer-graphics representation of the vehicle in a virtualreality environment; the result is almost like an interplanetary video game. The interaction between the virtual rover and its environment makes observation planning highly intuitive. It helps remote science team members to imagine being there in the field, which, in turn, helps to enable (for example, through guiding the rover's drives or the positioning of the instruments on specific parts of rocks or soils) many of the kinds of measurements that team members would actually make themselves if they were there.

This fusion provides a general model for successful future robotic, and human, remote field science. For example, the Curiosity mission's science and engineering team is using many of the operations and planning tools and structures of the MER mission, although necessarily modified for the specific attributes and constraints of that vehicle, landing site and mission objectives. Remote under-sea expeditions, as well as many other applications of telerobotics and telepresence, could similarly benefit from aspects of the MER model.

The human-centred computing aspects of missions such those of the Mars rovers have profound implications for the future of space exploration in general. For example, during the past few decades it has been popular to incite "humans versus robots" debates between advocates of crewed spaceflight and of robotic exploration. As Clancey makes clear, the debate is moot.

Humans are already exploring the Solar System using the tools of robotics and the methods of field science. Robotic companions - "intrepid" or otherwise - are absolutely going to be part of humanity's eventual in-person exploration of our planetary neighbours. It is not going to be humans versus robots, but humans and robots, working together.

Jim Bell is a professor in the School of Earth and Space Exploration at Arizona State University in Tempe and a member of the camera teams for the Sojourner, Spirit, Opportunity and Curiosity Mars rover missions. His Postcards from Mars is a photographic history of the Mars Exploration Rover missions.

e-mail:jim.bell@asu.edu

\section{Books in brief}

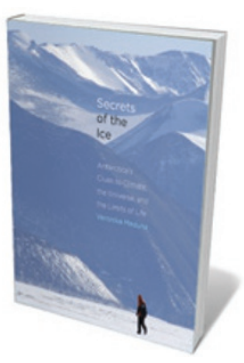

Secrets of the Ice: Antarctica's Clues to Climate, the Universe, and the Limits of Life

Veronika Meduna YALE UNIVERSITY PRESS 232 pp. £29.95 (2012)

Bleak and storied wonderland it may be, but Antarctica is also the world's biggest lab, where hundreds of scientists cluster to take the planet's pulse. Science writer Veronika Meduna follows the action in this homage to frontier science. Beginning with geological and glaciological findings on Antarctica's climate history, she segues into marine life, the microbes of the cold deserts and the fugitive 'hum' of the Big Bang chased by physicists and astronomers on the continent. A beautifully illustrated journey through 'Mars on Earth'.

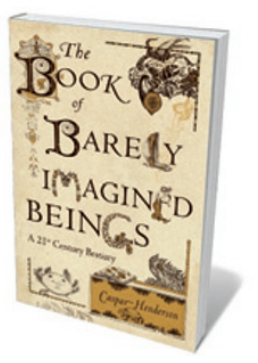

The Book of Barely Imagined Beings: A 21st Century Bestiary Caspar Henderson GRANTA 336 pp. £25 (2012)

Award-winning writer Caspar Henderson read Jorge Luis Borges's The Book of Imaginary Beings (1967) and realized that nature's creations often trump the fantastical for sheer surreality. Henderson's mainly marine beasts are a dazzling catch. The "genital fingered", gherkin-sized stomatopod Gonodactylus smithii, for instance, uses specialized limbs for defence - delivering enough force to break a bone. Eels, whales, arachnids and more are examined, with Henderson's central concern the survival of all this glory in the midst of the biodiversity drain. Wittily illustrated by Golbanou Moghaddas.

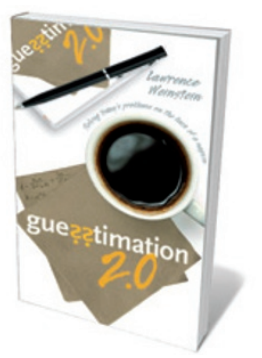

\section{Guesstimation 2.0: Solving Today's Problems on the} Back of a Napkin

Lawrence Weinstein PRINCETON UNIVERSITY PRESS 377 pp. £13.95 (2012)

This follow-up to the popular Guesstimation offers more on the joy of mathematical estimation, and inspiration for the budding analyst. Physicist Lawrence Weinstein trawls questions from the pragmatic to the bizarre. Among them are his probings of energy, transportation and recycling such as gauging the US plastic-bag pile-up on the basis of hydrocarbon use. He also covers the senses, heavenly bodies, radiation - and the amount of urine in public swimming pools.

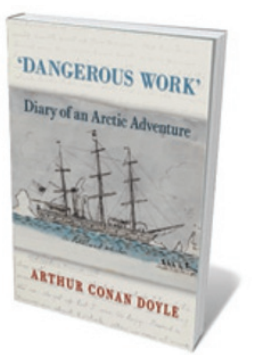

Dangerous Work: Diary of an Arctic Adventure

Arthur Conan Doyle (Eds Jon Lellenberg and Daniel Stashower)

BRITISH LIBRARY PUBLISHING 368 pp. £25 (2012)

Who knew that Arctic explorers lauded the creator of fiction's most famous sleuth for his own detective work on routes to the North Pole? Arthur Conan Doyle — author of Sherlock Holmes — published the data in the article 'The Glamour of the Arctic' after a youthful stint as ship's surgeon on a Greenland whaler. His diary of the 1880 voyage is here reproduced in facsimile, with published pieces inspired by the trip. Hair-raising incidents abound, from a sudden on-board death by peritonitis to the young medic's periodic falls into ice-strewn waters.

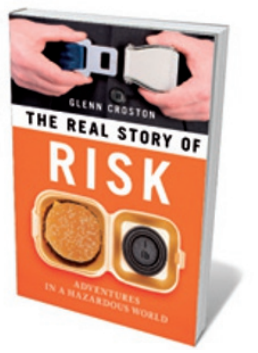

The Real Story of Risk: Adventures in a Hazardous World

Glenn Croston PROMETHEUs BOoKs 256 pp. £16.99 (2012)

Imagine this: you find yourself worrying about shark attacks while crossing a busy road in a daze. Our perception of risk and the reality are frequently at odds, biologist Glenn Croston argues in this jazzily written exploration of the balance between risk and reward. Croston marshals a raft of research on why our view of the phenomenon is so skewed, delving into evolutionary roots, our denial of 'slow' catastrophes, the role of lust in colouring our judgement, our need to belong and much more. 